\title{
Do educators realise the value of Bring Your Own Device (BYOD) in fieldwork learning?
}

Article

Accepted Version

Clark, K. A., Welsh, K. E., Mauchline, A. L., France, D., Whalley, W. B. and Park, J. (2021) Do educators realise the value of Bring Your Own Device (BYOD) in fieldwork learning? Journal of Geography in Higher Education, 45 (2). pp. 255278. ISSN 1466-1845 doi:

https://doi.org/10.1080/03098265.2020.1808880 Available at https://centaur.reading.ac.uk/92626/

It is advisable to refer to the publisher's version if you intend to cite from the work. See Guidance on citing.

Published version at: https://www.tandfonline.com/doi/full/10.1080/03098265.2020.1808880

To link to this article DOI: http://dx.doi.org/10.1080/03098265.2020.1808880

Publisher: Taylor \& Francis

All outputs in CentAUR are protected by Intellectual Property Rights law, including copyright law. Copyright and IPR is retained by the creators or other copyright holders. Terms and conditions for use of this material are defined in the End User Agreement. 


\section{CentAUR}

Central Archive at the University of Reading

Reading's research outputs online 


\title{
Do educators realise the value of Bring Your Own Device (BYOD) in fieldwork learning?
}

\author{
Abstract \\ This paper explores the benefits, barriers and challenges of BYOD (Bring Your \\ Own [mobile] Device) in fieldwork teaching through the views of Higher \\ Education practitioners who have and have not used BYOD in fieldwork. While \\ the use of BYOD has been explored within classroom settings, there are few \\ studies on the use and impact on BYOD in fieldwork.--This study investigated the \\ educational benefits of BYOD and the barriers and challenges associated with \\ BYOD in the field. Students were willing to use their own devices in the field \\ and were engaged through the use of BYOD. Practitioners noted various benefits \\ to using BYOD, including student engagement and familiarity with their own \\ devices, potentially increasing time available in the field. Practitioners also \\ highlighted a number of challenges and potential challenges with BYOD \\ including supporting a range of devices, incompatibility and the potential for \\ inequality.
}

This paper also explores the use of mobile technology in fieldwork through the SAMR (Substitution, Augmentation, Modification, Redefinition) model and discusses the potential for BYOD to change practice.

Keywords - BYOD; Bring Your Own Device; fieldwork; pedagogy; technology

\section{Introduction}

The concept of Bring Your Own Device (BYOD) is the idea that an individual makes use of their personally-owned technological device (e.g. smartphone or tablet computer) in a workplace or educational setting, rather than using an institution-owned device, to perform work or education related tasks. BYOD has been used in classroom and work settings to support learning, cut institutional costs and enable or support work to continue outside of the classroom or workplace; see for example, Afreen (2014), Nykvist (2012) 
and Siani (2017). However, there has been little study on the use and value of BYOD in fieldwork activities in Higher Education (HE).

Fieldwork is an important component of learning and teaching in geography, earth and environmental sciences (Fuller et al., 2006, Maskall and Stokes, 2009, Maw et al., 2011). The use of mobile computing devices such as smartphones, tablet computers, and the concept of BYOD, would seem to be suited to fieldwork (Whalley et al., 2018, Munge et al., 2018). Portable technology can provide users with a wide range of functions while working in the field; from taking photographs, digital input of field data to species identification (Meek et al., 2013, Whalley et al., 2018).

Use and benefits of mobile technology in fieldwork

Gardiner and Unwin (1986) demonstrated the importance of using computers in field classes to work on data and reports before mobile devices were available. Various studies have shown how technology can lead to diversity in teaching and assessment of fieldwork and support student's skills development, for example France and Ribchester (2004). However, early studies on introducing mobile technology into fieldwork suggested limited pedagogic value; Fletcher et al. (2007) considered the introduction of mobile technology in fieldwork may have been driven more by technological than pedagogical innovation. Woodcock et al. (2012) found that many students who owned smartphones were "largely unaware of their potential to support learning” but importantly, found they were "interested in and open to the potential as they become familiar with the possibilities". Tablet computers, such as the iPad, were first available around in 2010. Data from Ofcom (2018) shows $11 \%$ of UK households had a tablet computer in 2012, rising to 58\% in 2018. Smartphones and touchscreen smartphones have been available since 2007 for-. In $2012,39 \%$ of UK adults owned a smartphone, increasing to $78 \%$ in 2018 (Ofcom, 2018). Studies into mobile device use in the 
classroom and fieldwork reflect this increasing ownership. For example, Welsh et al., (2015), France et al., (2016), and Welsh et al., (2018) show evidence of broad skills development (beyond computer literacy) and demonstrate how mobile technologies in the field can provide a diverse range of pedagogic benefits.

In Welsh et al. (2013), HE practitioners described the key benefits of using mobile technology to support field learning as more efficient data capture and processing; the development of technology and IT skills, the facilitation of reporting, communication and the enhancement of the field experience generally. A single item of mobile technology such as an iPad can provide multiple functions including GPS receiver, camera, video recorder, and dictaphone. Echoing this, Whalley et al. (2018) highlight the benefits of an iPad (and iPhone) in fieldwork, particularly its multifunctionality. In addition, devices can host apps for word processing and data analysis, for less expense than the cost of the individual items of technology. A significant benefit highlighted by Welsh et al. (2013) was the ability to analyse field-collected data while still in the field; ensuring sufficient data were collected and enabling students to start interpreting the results while still immersed in the fieldwork environment. The development of students' technological skills was also seen as a pedagogic benefit. Welsh et al. (2015) surveyed their students' views on using mobile devices in fieldwork learning after using university-owned iPads in the field. Students identified the key benefits as portability, the multi-tool aspect of iPads, and practical features such as convenience and speed of use. However, students were concerned about the potential for damaging devices in the field (for example impact or water damage) although these concerns were reduced by the provision of protective cases. Unreliable internet access and reduced connectivity was also highlighted as a problem. Welsh et al. (2015) noted differing ideas for the use of iPads between staff and students; students saw them as a 
technological tool, teaching staff as a learning tool with pedagogic benefits. Welsh et al. (2013) also found some reluctance among staff to use technology in fieldwork. This is thought to be due to a lack of training or not fully considering the pedagogic benefits of mobile technologies.

Welsh et al. (2015) raise staff concerns that students will not know how to use equipment. However, as tablets and smartphones become ubiquitous, students may be better able to use them in classroom or fieldwork setting. Students recognise and value the skills learnt in the field through using mobile apps (France et al., 2016) and note such skills can be transferred to future assessments and employment. Having used mobile technologies in the field to support their learning, many students felt that using mobile apps helped them to become more effective researchers.

Welsh et al. (2018) found that students noted the benefits of using their own device in fieldwork, enabling faster and more efficient working as they were familiar with the capabilities of their device and could personalise it to their specific learning needs. A number of studies have investigated the use of mobile devices by students whilst on placement. In Wishart's (2011) study, students undertaking teacher training were given handheld PDAs (Personal Digital Assistants), whilst Lumsden's (2012) study followed medical students on placement who had been given iPads. In both cases students found these mobile devices supported their learning, especially while on placement (i.e. away from formal teaching). Stagg and Donkin (2017) found students to be enthusiastic about the ease of using mobile devices in the field. France et al. (2016) found students recognised the links between using a variety of apps on mobile devices in fieldwork and the development of graduate skills and attributes such as research literacy and digital and information literacy. Miller and Welsh (2017) noted that students valued the engagement through the interactivity that BYOD could provide. 


\section{Student views of BYOD}

Various studies have found students to be positive about BYOD in a classroom setting. Derounian (2017), Siani (2017) and Miller and Welsh (2017) all found students to be positive about the benefits of BYOD in the classroom for various activities, including researching additional material and taking part in interactive formative assessments.

In the field, students have also been positive about using BYOD and mobile technology. Thomas and Fellowes (2017) used BYOD for species identification. The majority of students were happy to use their own devices in the field and noted the benefits of using them to enhance learning at later date. Welsh et al. (2018) found 79\% of students undertaking a range of Geography and Biology based fieldwork activities were willing to use their own device for a variety of tasks including qualitative and quantitative data collection. Those who were not willing to use their device often had concerns about damage. Priestnall et al. (2019) trialled a variety of mobile technologies with students for augmenting landscape scenes in fieldwork and students responded positively to the interactivity.. However, there were again concerns about usability in the field and potential damage to equipment. Newman and Jones (2008) and Jarvis et al. (2016) developed digital audio and audio-visual tours for mobile platforms (including mobile phones and smartphones) in order to develop students' observational skills within urban settings.

Using BYOD requires students to own a device capable of running the apps or recording the data. Is it realistic to expect students will have, for example, a smartphone or tablet? As discussed previously, the majority of 16-24 years olds in the UK own a smartphone and over half own a tablet computer (Ofcom, 2018). Thomas and Fellowes (2017) found $71 \%$ of students taking part in a fieldwork BYOD study had their own 
smartphones, while Miller and Welsh (2017) found 92\% of students participating in a BYOD classroom study had access to or owned a smart phone.

However different models and makes of smartphones and tablets can have different capabilities. The potential for inequality, not simply owning or not owning a device, but owning a device suitable for the tasks to be undertaken, is highlighted in a number of BYOD studies (for example Miller and Welsh (2017), Welsh et al., 2018).

Outside fieldwork, BYOD also offers the potential for universities as a whole to rely less on computer labs / suites and university owned devices. Nykvist (2012) describes a science-based course where, instead of booking time in the university computer labs, students met in an open space and used their mobile device, or a university-supplied iPad to complete tasks. With a large number of students owning their own laptops, tablets and smartphones (Ofcom, 2018) open access Wi-Fi and 4G networks having wider coverage, the accessibility advantages in students using their own familiar or adapted equipment and the potential for cost savings to universities, is there an appetite for BYOD to spread more widely across higher education?

\section{BYOD vs. university devices}

Using university-owned devices means students have the same equipment with the same capabilities, there will be a known number of devices for individual or group work, teaching staff know what apps are loaded, what the device is capable of and (hopefully) how to troubleshoot any problems. So why use BYOD?

BYOD can enable more personalised, flexible learning. Students are able to personalise and adapt the technology, and the learning environment the technology provides, to suit their needs (Whalley et al., 2014, Whalley et al., 2018). Work can be kept on students' own, easily accessible, devices and returned to at a later date (Thomas and Fellowes, 2017). BYOD also has implications for accessibility. Students with 
specific needs can have pre-adapted technology and equipment. Tablets already have good accessibility features built in and coupled with bluetooth devices and digital pencils make life easier for any student as well as those with accessibility problems. Being able to use these devices in the classroom and in fieldwork supports learning (Jisc, 2016). Mobile devices can support accessibility in various ways, for example digital books and documents can be "read aloud" by an iPad (Nuttall and Nuttall, 2013), Grussendorf (2013) found students used mobile phones and tablets to record lectures so they could be referred to again at a later date, supporting students who may not be able to take comprehensive notes at the time.

As highlighted previously, the majority of students will own a smartphone and are familiar with it. This familiarity could reduce the time required in the field to record and process data, giving more time to undertake tasks (Welsh et al., 2018). There is also the potential to develop new learning activities, and associated skills in students, through the use of BYOD (for example, Whalley et al., 2014, 2020 and Fabian and MacLean, 2014).

Using university owned devices can have a number of disadvantages. Miller and Welsh (2017) noted that BYOD has the potential to reduce long-term costs as universities are not having to purchase technologies which can rapidly become obsolete. Devices need maintenance and updating, costly in terms of both time and money. Ensuring all devices have the required apps could take a significant amount of time in comparison to notifying all students to download a set of apps. If a limited number of devices are available it may not be possible for every student to have a device and if two groups are wanting to use the technology who gets priority? Sharing devices between pairs and groups of students can also be problematic. In groups or pairs one student could dominate a single device, leading to a lack of involvement by other group 
members (Fabian and MacLean, 2014; Welsh et al., 2018). One student moving at a different pace to the others could also cause tensions, with others feeling pressured to slow down or speed up in order to complete an activity (Fabian and MacLean, 2014). This might also be an issue with BYOD if devices need to be shared. A smartphone or tablet can be considered a very personal space with students unwilling or uncomfortable sharing their own device or having to use someone else's (Welsh et al., 2018).

The flexibility and opportunities for using BYOD outside of "formal" learning activities is also reflected in Citizen Science, where volunteers can, for example, contribute to extensive surveys of species and wildlife for example, the Natural History Museum (http://www.nhm.ac.uk/take-part/citizen-science.html), and the Centre for Ecology and Hydrology (https://www.ceh.ac.uk/citizen-science). The citizen scientists would be using BYOD, and the flexibility of the project, participants' familiarity with their own device and capabilities, and "taking work home" is key.

\section{Pedagogic benefits and pitfalls of BYOD}

Could BYOD be a distraction to students? Using their mobile phones and tablets could mean access to distractions such as social media. Derounian (2017) looked at mobile phone use in a classroom context, specifically in sessions where the technology was not necessarily needed. There was a mix of uses, some students would search out material relevant to the current teaching session, while others were using it as a distraction. It is worth noting that these were sessions where students had chosen to use their mobile phones and were not undertaking set tasks. Siani (2017) noted some concerns with students using social media during sessions when mobile phones were being used for formative assessments. However, the field environment is very different to that of the classroom and Welsh et al. (2018) found that, although students using BYOD on field 
courses had some concerns about the potential distractions very few students noted it as a concern.

Considering how these "non-work" uses can be used to support learning could also be important within BYOD, for example using Twitter and Facebook to build and encourage group discussion (Welsh et al., 2015; Peacock and Bacon, 2018). This should also be considered in light of how teaching staff are encouraged to use social media in some instances. For example, Tweeting in and about academic conferences and sharing information is now common (see, for example, the EFL project twitter feed https://twitter.com/fieldwork_ntf).

\section{Pedagogic benefits}

Many of the pedagogic benefits of BYOD have been discussed previously, for example the flexibility of the learning spaces they provide, familiarity with devices leading to enhanced learning, opportunities to introduce new learning activities and styles of learning. BYOD could also lead to a change in the way fieldwork and the assessment of fieldwork is undertaken. The use of mobile devices and BYOD gives opportunities to redefine how fieldwork is undertaken in ways that could not have been envisaged prior to mobile technologies.

The SAMR model (Substitution, Augmentation, Modification, Redefinition) (Puendetura, 2009) can be viewed as a method for evaluating how technology (specifically computing technology) can impact on teaching and learning; by highlighting "progression". There are four stages to the model:

- Substitution - Technology acts as a direct tool substitute with no functional change 
- Augmentation - Technology acts as a direct tool substitute with functional improvement

- Modification - Technology allows for significant task redesign

- Redefinition - Technology allows for the creation of new tasks previously inconceivable

For example, Fabian and MacLean (2014) adapted course materials for FE students on various programmes, they then used the SAMR model to explore the use and adaptation of course materials and students' reactions to them. This process of evaluation to ensure that the technology is supporting learning in fieldwork is relevant to BYOD to avoid situations where students undertaking fieldwork become focussed on engaging with the (mobile) technology rather than the learning process (Meek et al., 2013) or reduce the time spent in the field, resulting in students not developing the intended field skills (Munge et al., 2018).

The overall aim of this research is to investigate how and why practitioners view and use BYOD in fieldwork. Here we report on a survey and telephone interviews undertaken with fieldwork practitioners regarding the use of BYOD in the field, the results are interpreted in the context of the SAMR model and recommendations made to individuals, Schools and Universities that are trying to enhance fieldwork learning via BYOD.

\section{Methods}

Practitioner's experiences and views of BYOD in fieldwork were gathered via two routes, an online survey and follow-up telephone interviews. 


\section{Online survey}

Higher Education practitioners were a self-selecting group who had been involved in previous surveys of fieldwork, Enhancing Fieldwork Learning (EFL) events, signed up to a fieldwork / technology email list or whose name had been passed on by a colleague. They were contacted by email and invited to complete the survey which was conducted using Survey Monkey (https://www.surveymonkey.com/). Additional respondents were recruited via an open invitation on Twitter; therefore, the survey was open to respondents globally.

The survey was developed by the authors with the aim of exploring the benefits and challenges of implementing and using BYOD within an HE fieldwork context.

Survey participants were asked about the type of fieldwork they were undertaking, their experiences of using BYOD in the field and their opinions of BYOD, whether they had used it in the field or not. Questions required a range of responses including yes / no answers, responses on a Likert scale and free text responses. The survey asked about the barriers and challenges to implementing BYOD, the practicalities of using BYOD, student responses to BYOD and the educational benefits of BYOD. Practitioners were not asked to differentiate between the devices that were used in the field but were asked if students had used their own device, for example a smartphone or tablet computer. The full survey is available in appendix 1 . The survey was undertaken September - November 2015 and all responses have been anonymised for reporting. The majority of survey respondents were based in the UK (6 were international, $65 \mathrm{UK}$ ) and all were based at HE institutions. Respondents were from a range of disciplines including Geography, Earth Sciences and Biology. 


\section{Phone interviews}

At the end of the online survey participants were asked if they would be willing to take part in a phone interview to further discuss their views and experiences of BYOD. Thirty-five responded positively, and of these twenty were randomly selected to take part in the phone interviews, ten who had undertaken BYOD, ten who had not. All the phone interviewees were based in UK HE institutions and were working in Geography or Biology. The interviews were based around the following five open ended questions which considered the both educational impact and practitioners experiences of BYOD.

(1) Do you believe there are any educational benefits of using BYOD for student learning in fieldwork education? Please elaborate.

(2) Do you believe there are any negative impacts of using BYOD for student learning in fieldwork education? Please elaborate.

(3) How could BYOD change your educational practice?

(4) How do the educational impacts differ between BYOD and institutional provision of devices?

(5) How do you believe that the use of BYOD could impact on the educational experience of your students?

Practitioners were contacted for phone interviews between January and April 2016 and the research approach received ethical clearance from the School of Agriculture, Policy and Development, University of Reading. Interviews were approximately 30 mins long and were recorded. Subsequently, thematic analysis (Braun and Clarke, 2006) was used to explore the emerging key themes. 


\section{Results}

\section{Respondents}

There were 71 survey responses. Respondents were from a range of disciplines (e.g. Biology, Geography, Archaeology, Earth Sciences and Management). Fieldwork ranged from 2 hours to 2 weeks in duration and fieldwork groups from less than 10 to greater than 100 students.

Seventeen phone interviews were conducted. Ten were with practitioners who had used BYOD and seven with practitioners who had not. Fieldwork was both UK and international and Biology or Geography focussed.

Survey participants were asked to rate their own technological abilities, $19 \%$ $(n=69)$ of participants rated themselves as extremely able, 51\% (n=69) as above average, $23 \%(\mathrm{n}=69)$ average, and 7\% $(\mathrm{n}=69)$ below average ability

In the survey there was an almost even split between practitioners who had used BYOD for fieldwork $(54 \%, \mathrm{n}=71)$ and those who had not $(46 \%, \mathrm{n}=71)$. Of those who had used BYOD, 58\% ( $\mathrm{n}=33)$ stated that the BYOD activity in the field had been planned by a practitioner, $24 \%(n=33)$ that it was student initiated and $18 \%(n=33)$ that it had been a mixture of both student led and practitioner planned.

Main drivers for use

Practitioners who had used BYOD for fieldwork were asked to cite the main drivers for using it. The three main drivers highlighted were: convenience or familiarity with the student's own device ( $20 \%, \mathrm{n}=33)$, limited or no university kit available to the students $(15 \%, \mathrm{n}=33)$, to reduce costs $(10 \%, \mathrm{n}=33)$. Other drivers included student engagement with the topic and BYOD making it easier for students to record data. One practitioner commented that students were, "wanting to take photos on their own devices so they had them readily available after the fieldwork for their reports" and 
"Easier to record data. Saved time later in inputting data to spreadsheets" another noted that it was their "Own initiative, done informally to increase their own knowledge". Practitioners indicated that students used their own devices during fieldwork in a range of different ways. The most frequent uses were taking photographs $(21 \%, \mathrm{n}=80)$, for digital storytelling $(15 \%, \mathrm{n}=80)$ and for data collection $(11 \%, \mathrm{n}=80)$. Practitioners also noted that students used apps on their devices for fieldwork, some specific examples given were Fieldtrip GB, Dropbox, Facebook and species identification apps. Two of the examples focussed on collaborative and group work:

- "Collaborative work in small groups: each student contributing photos and/or text to a shared 'wall' using Padlet software. For one field trip the students were then required to produce a photographic essay of the fieldwork destination."

- "Creation of group videos (instead of traditional presentation). Students have also sometimes created own video for fun."

Practitioners were also asked about app use in the field, $73 \%(n=30)$ of practitioners stated that they specifically used apps for fieldwork which did not rely on a Wi-Fi or 3G, highlighting that Wi-Fi in the field could be patchy and that on an international fieldtrip $3 \mathrm{G}$ and $4 \mathrm{G}$ connections were too expensive for many of their students to use. If a student did not have their own device, a number of alternatives were offered by practitioners. The most common was to provide university or field centre owned devices $(28 \%, \mathrm{n}=46)$, students were also asked to work in groups $(24 \%, \mathrm{n}=46)$ or to share their devices $(17 \%, \mathrm{n}=46)$. Some practitioners $(13 \%, \mathrm{n}=46)$ stated they always offered a non-digital alternative, so students did not feel under pressure to use their own devices. 


\section{Benefits of BYOD}

In the online survey both practitioners who had and had not used BYOD were asked to reflect on the benefits of BYOD in the field. The top 5 responses are given in Table 1.

Table 1 near here.

In terms of pedagogic benefits survey respondents also noted that the "Innovative use of tech that engaged and motivated them" and "It speeded up their engagement with starting to achieve their LOs [Learning Outcomes]'. Learning Outcomes describe the knowledge or skills students should have acquired by the end of the (in this case) fieldwork and can support students in developing these skills or knowledge.

Practitioners who had used BYOD were also asked if using BYOD had speeded up or slowed down the learning activity. Just over half $(52 \%, \mathrm{n}=16)$ stated that it had speeded up the activity in comparison to $32 \%(n=3)$ who stated it had slowed down.

In the phone interviews, practitioners were asked specifically about the educational benefits of BYOD. Practitioners who had used BYOD identified a wider range of educational benefits that those who had not. These benefits included (but were not exclusive to) familiarity, retention of data, focus on learning, no cost to department and enhanced employability. Empowering students and the potential for new styles of learning were also identified as benefits.

Practitioners in the phone interviews who had not used BYOD identified some, but not all, of these benefits citing: familiarity, focus on learning and students always having the devices with them as benefits. Familiarity was seen as the greatest benefit, 
for a range of reasons including being able to focus on learning rather than having to learn how to use the technology.

Practitioners in the online survey also commented on the educational benefits of BYOD:

- "It allowed students to be more independent during fieldwork and also helped them think critically about the apps they had downloaded, perhaps this also helped them think about species identification features"

- "Liberates them to work independently"

- "Students recognise the usefulness of the tools they already own and thus they are encouraged to collect data on their own or for other classes or projects"

\section{Challenges and barriers to using BYOD}

Practitioners taking part in the survey who had used BYOD were asked about the greatest challenges, those who had not used BYOD in fieldwork were asked to outline what they perceived to be the barriers preventing them from using BYOD (Table 2).

Table 2 near here.

Of the practitioners who had not tried BYOD, $80 \%(n=30)$ thought that students would be willing but $20 \%(n=30)$ did not know if students would be willing to use their own device.

In the phone interviews the challenges of BYOD identified by both those who had and had not used BYOD were similar. Those who had used BYOD identified (in order of likelihood): inequality, distraction and range of devices as the key challenges. 
Those who had not used BYOD identified: distraction, range of devices, set up time, inequality and insurance as key challenges.

It is interesting to note that inequality (i.e. some students not having a device, or inequality between devices) was identified as a potential challenge by nearly all practitioners who have used BYOD (this was highlighted in both the survey and the phone interviews). They have used BYOD but realise that inequality is, or could be, an issue.

Management of devices was raised as a challenge in the phone interviews. Those who have used institutional devices identified how challenging managing a class set of iPads is in terms of time and logistics and welcome the idea that students manage their own devices. However, both those that have not used BYOD identify that managing a range (makes, models, capabilities) of devices is itself a challenge and therefore institutional devices with known capabilities are preferred.

In the survey, practitioners who had used BYOD were asked about managing problems whilst using BYOD in the field. None of the respondents noted any specific problems that had occurred in the field, however many had alternatives to BYOD, for example: "Loan them my own stuff. Make sure there are non-digital alternatives." And "We had the paper contingency but thankfully didn't need it." Some practitioners noted that "Problems were associated with lack of experience of students" and would provide extra support when and where it was needed.

\section{Student feedback}

Survey respondents who had used BYOD were asked whether students found using BYOD in fieldwork to be a positive or negative experience; $68 \%(n=30)$ of respondents found BYOD to be a positive experience for students, as opposed to $3 \%(n=30)$ who found it to be a negative experience. Comments from practitioners indicated that 
students had enjoyed using BYOD and that some students had commented positively on the innovative nature of BYOD.

The survey also asked practitioners if using BYOD led to greater student engagement with fieldwork in comparison to using institution owned devices. Just under one-third of responses $(31 \%, \mathrm{n}=11)$ stated that "yes", using BYOD had led to greater engagement, $35 \%(\mathrm{n}=12)$ said BYOD had not led to greater engagement. The remaining $35 \%(\mathrm{n}=12)$ had not used institutional devices.

Although not specifically asked about student feedback in the phone interviews practitioners who had used BYOD commented on student reactions to it and how the process and assessment of fieldwork had changed as a result of BYOD.

- "Students now make short films instead of posters, they enjoy this and can spend more time on data collection and new skills."

- "Students can often start off negatively and then end the experience positively."

- "Students felt that this type of assessment was more relevant and in tune to their lifestyle compared to typical report or essay-based assignments."

In relation to engagement practitioners in the survey commented on how BYOD had supported engagement with fieldwork, for example: "Got them engaged with topics and increased participation and depth of learning”. One practitioner commented that BYOD "Reduced the time needed to input and analyse data - this helped when assessment preparation time was limited, allowing more time to focus on the results and discussions"

In the phone interviews practitioners made similar comments, some noting that BYOD had led to more effective or deeper learning. One practitioner commented that 
"It is one less thing for them to understand so they can focus on the learning when in the field". Figure 1 shows a word cloud of the key words and themes of the responses from all phone interviews to the question "Do you believe there are any educational benefits of using BYOD for student learning in fieldwork education? Please elaborate."

Figure 1 near here.

The word cloud highlights the most commonly used words and phrases, those used most frequently are shown in a larger font size. When the wordcloud was visually analysed the most prominent words and phrases were: student driven, data recording, familiarity and immediacy. This suggests benefits to the students through being an easily accessible and familiar tool to support fieldwork learning and that it was something the students themselves wanted to use.

\section{Changing Practice}

All of the practitioners taking part in the phone interviews who had used BYOD said that it had changed their practice. Two examples, and one practitioners' thoughts on how fieldwork could be changed by BYOD, are given below:

- "Students now make short films instead of posters, they enjoy this and can spend more time on data collection and new skills. The film goes on the departmental YouTube and students can share the URL with their potential employers."

- "Change to assessment - before they were assessed on reports about data. Now assessed on how they design survey and how they manipulate data... Assessing a different skill set. Students appreciate that. They always want assessment that is more practical to their lives beyond academia." 
- "Student could design their own fieldwork, their own devices would come into play a lot more as they can see where they can apply them."

Half of all the practitioners who took part in the phone interviews said they could see how BYOD could potentially change their practice. However, their reservations included: lack of own experience, a need to see real examples of it in practice and staff reluctance to using BYOD.

\section{Support for BYOD}

Practitioners who had used BYOD were asked in the survey about the support available for implementing BYOD in fieldwork within their own institution. 12\% $(n=34)$ felt they were supported by their institutions in implementing BYOD, whereas $38 \%(n=34)$ felt they received no or little support in implementing BYOD.

When asked "what more could your institution do to support you?", 66\% $(\mathrm{n}=32)$ said training courses, $50 \%(n=32)$ mentors and $47 \%(n=32)$ financial support. Other comments on support included providing staff with iPads - giving them the opportunity to explore the technology - and supplying technology for those who didn't have devices that could be used for BYOD.

\section{Discussion}

BYOD has emerged as a concept which enables students to choose, personalise and adapt their own platform for learning. However, it also presents real challenges in terms of how to support and enable such an engagement. There also needs to be a consideration of the educational and pedagogic benefits that BYOD can provide so practitioners can ensure BYOD is not "tech for tech's sake" and that the potential for BYOD to support learning in the field can be fully realised. 


\section{Benefits of $B Y O D$}

In both the survey and phone interviews practitioners who had and had not used BYOD discussed a range of both practical and educational benefits to using BYOD, including student engagement, familiarity with using the device, ownership of data, improving data collection and skills and cost saving. In some instances, BYOD was student initiated. Students used their devices unprompted to take photos or refer to resources while in the field to support their learning.

The survey highlighted a mismatch between those practitioners who have used BYOD and those who have not. Those who had used BYOD highlighted familiarity as the biggest benefit, whereas for those who hadn't used BYOD the biggest perceived benefit was student engagement.

Why is familiarity a benefit? Students' familiarity with their device could give more time for undertaking learning tasks and engaging with the learning process rather than spending time getting used to new equipment. Practitioners responding to the survey made a number of comments relating to how students' familiarity with their devices had supported their learning and engagement with fieldwork. One practitioner noted that "It speeded up their engagement with starting to achieve their LOs [learning outcomes]" another noted that familiarity with the device they were using "Reduced the time needed to input and analyse data - this helped when assessment preparation time was limited, allowing more time to focus on the results and discussions."

Familiarity with devices was noted as a benefit by students in BYOD by Welsh et al. (2018), and familiarity with particular apps by Priestnall et al. (2019). Time and effort in learning how to operate an unfamiliar device or app was not needed, therefore enabling students to focus on the learning task. Practitioners in this study commented about students' familiarity with their devices: "Students don't consider using their own phones in particular as "using technology" as they are often so intertwined with 
everyday life" (phone interview). One practitioner said that in their experience “Traditional 18-21 year olds are used to using apps and devices 'it's part of their culture'... More mature students may be more hesitant but have been quite open" (phone interview).

Practitioners taking part in the survey also shared examples of how using BYOD had encouraged students to spend more time and become more engaged with specific tasks:

- "Enriched sharing of results. Deepened interpretation of data"

- "Slowed down in a good way, they spent longer engaged in the task."

- "Activity takes longer and learning is accelerated, broadened and deepened."

This engagement while in the field, while supported by mobile technology was also noted by Meek et al. (2013). Students were able to start analysing and interpreting data they collected while still in the field, enabling further data collection if needed. Engagement with learning in fieldwork has previously been noted as a potential issue, with students not engaging with learning activities both during and after fieldwork. BYOD could offer both an engaging way of "doing" fieldwork and undertaking fieldwork related tasks once out of the field (Munge et al., 2018).

Of the practitioners responding to the survey who had not tried BYOD the majority (80\%) thought that their students would be willing to use their own device. Of those who had used BYOD only $2 \%$ noted that students were unwilling to use their device for fieldwork.

However, some students may still be unwilling to use their own device (Welsh et al, 2018). This unwillingness, coupled with concerns about inequality noted by practitioners in this study, highlights the need for alternatives or back-ups. It also 
highlights the need for preparation in advance of BYOD for both students and practitioners.

Unwillingness to use BYOD could be countered by working with students, showing how they can effectively use BYOD, how they can use the technology for new and innovative tasks and learning activities. By demonstrating how BYOD could free up time from learning how to use specialist equipment, giving more time in the field for fieldwork. This could also counter problems with devices not working as expected. If students are well briefed in using the technology they could troubleshoot problems themselves, developing their own technological abilities and skills they can use beyond the field (France et al., 2016).

Developing practitioners' technology skills on a variety of devices and platforms (e.g. Apple and Android), could reduce the potential for problems in the field. Although practitioners in this study rated their technology skills as good, some still commented on the difficulties they faced in dealing with multiple platforms and the variety of devices they could encounter when using BYOD. One practitioner in the survey commented that they encountered problems when developing a plant identification app that would work on both Apple and Android platforms. Issues around developing, for example apps and learning activities, to work on different platforms has been highlighted in the past (for example; Nykvist, 2012; Fabian and MacLean, 2014; Cliffe, 2017). Perhaps BYOD could also provide an opportunity for working with students and potentially across institutions. Collaboration might support the development of, for example, apps for fieldwork tasks or evaluating the best uses of mobile technology in fieldwork. Priestnall et al. (2019) and Jarvis et al. (2016) involved students in the evaluation of various mobile technologies in augmenting landscape scenes and mediascapes. Munge et al. 
(2018) highlight the opportunities for technology use in fieldwork to support student skills development and cross-disciplinary sharing of practice and expertise.

\section{Practical benefits}

In addition to the educational benefits, practitioners in both the survey and phone interviews noted practical benefits to BYOD, including reduced institutional costs, time saving in terms of device management, and using devices for work outside of fieldwork. Those who had not used BYOD viewed reducing costs as more of a benefit than those who had.

In terms of time management, practitioners saved time not having to keep university owned devices updated with relevant apps. Students manage their own device, encouraging them to get more out of their smartphone or tablet. Using their device in the field could also give students the opportunity to "unlock" its

capabilities in terms of a learning device. Development of students' capabilities and potential for use in other areas of teaching and learning as well as supporting employability skills development are also important (France et al., 2016; Munge et al., 2018).

BYOD enables students to have easy access to data after the fieldwork and this was seen as beneficial by practitioners in both the survey and the phone interviews. Students were able to access and work on data out of the field, extending their learning and meaning more practical work / collection of data could be done with the limited time available in the field. The use of mobile technology in fieldwork has been shown in various instances to extend learning beyond the field and the initial fieldtrip (Meek et al., 2013; Thomas and Fellowes, 2017; Munge et al, 2018)

\section{Challenges of $B Y O D$}


Practitioners in the survey highlighted challenges with both using and implementing BYOD. For those who had used BYOD the biggest challenge was inequality, then incompatibility (of devices) followed by the potential for damage to student's devices. For those who had not used BYOD the biggest challenge to implementing BYOD was inequality, then lack of time, followed by a lack of practitioner knowledge and difficulty in supporting a range of devices.

\section{Inequality}

Practitioners taking part in the survey who had had not used BYOD listed inequality as the greatest challenge to BYOD. Although over $90 \%$ of students are likely to own a smartphone (Ofcom, 2018), different models and makes may not be capable of the same tasks. Inequality could be considered in terms of not just having a smartphone or tablet, but not having a device capable of (for example) running the app required to undertake a task. One practitioner in the survey noted concerns from students that it would be "fairer" for students to have a device supplied by the university - putting everyone on an equal footing.

Phone interview participants also identified inequality as a key challenge of BYOD. Several noted that although inequality could be an issue it was becoming less of one, with the majority of students owning a device the work could be completed on. However, both those who had and those who had not used BYOD identified inequality as one the main challenges. Some commented on different aspects of inequality, for example one practitioner (survey) noted that students "May have limited $3 G$ on their contracts so if we ask them to use that data in the field, it could be a problem. Can't rely on them being able to afford to use the internet." This affordability of BYOD for students has been highlighted in previous studies (for example Nykvist, 2012) and was also raised in several phone interviews. One interviewee also commented that: 
"Perhaps practitioners are focusing on the wrong aspect of inequality (i.e. own a device versus do not own a device) and should instead focus on how to educate students prefieldwork about suitable apps that they may want to download in advance of the fieldwork." noting that some aspects of inequality may be simple to rectify.

Students have also raised inequality as one of the biggest challenges to BYOD (Welsh et al., 2018), notably the inequality between different devices. Care needs to be taken that students don't feel excluded or disempowered by BYOD, one practitioner in this study (phone interview) highlighted an instance where BYOD had inadvertently lead to students avoiding post-fieldwork sessions: “...some students felt alienated if they didn't have the most up to date devices. Two didn't come to the sessions after than as they felt as though they didn't have the right device to do the work on."

So how could inequality be mitigated? Practitioners discussed taking care in ensuring students could complete the tasks on the devices they have or ensuring an alternative to a student's own device was available. One practitioner in the survey said that they had not encountered any problems with inequality as the tasks that required BYOD were taking photos or video, applications standard on smartphones. Preparation could also be a key aspect of reducing or removing inequality. This could involve ensuring students have, for example, appropriate apps loaded, that these apps function correctly, and not relying on $3 \mathrm{G}$ or $4 \mathrm{G}$ internet access for work to be completed, also important to consider for fieldwork in remote areas (Welsh et al., 2015).

As discussed previously, different devices and platforms (e.g. Android vs. Apple) could also cause problems in terms of technical support. Although $70 \%$ of the survey respondents rated their technological ability as higher than average, practitioners may not have knowledge of all the platforms and devices in use. Practitioners in the phone interviews identified potential problems, for example: 
- "Supporting different operating systems, Difficult to help students with their devices, wouldn't be a problem if it was an institutional device"

- "Need to develop material that can be delivered on multiple devices"

These comments were mirrored in the survey where practitioners who had not used BYOD, when asked about barriers to BYOD, highlighted a lack of knowledge in supporting students to use their own devices and the challenge of supporting a range of devices as issues. Those who had used BYOD saw students having incompatible devices (e.g. devices on which specific apps would not function) to be a challenge.

\section{Damage}

The potential for damage to devices and device insurance were raised by both those who had and those who hadn't used BYOD in both the survey and phone interviews. Issues around damage were also raised by students in Welsh et al. (2018), where it was considered a major concern. While there are ways of mitigating potential damage, for example shock proof cases, using a zip-lock bag to prevent water damage (Welsh et al., 2015), BYOD in a classroom setting has less likelihood of damage in comparison to fieldwork setting.

One of the main issues with damage, highlighted in the phone interviews, was where did the responsibility lie if a student's device was damaged during fieldwork? This is an aspect of BYOD which warrants further exploration. Although, in this study, students were happy to use their devices in the field, whose insurance is liable if there is damage? Do students have insurance for their mobile devices? One survey respondent also noted theft as a potential problem: "someone tried to steal their iPad when they were collecting data". 
Does the potential for damage make students less likely to use their devices in the field? Are they more likely to use phone than tablet as it is easier to handle, protect and transport? Practitioners in this study found overall, students were willing to use their own devices, as demonstrated in previous studies (for example: Thomas and Fellowes, 2017; Welsh et al., 2018). Although there was concern about the potential for damage no respondents in the survey or telephone interviews highlighted any instances of damage. Welsh et al. (2015) found students willing to use iPads for fieldwork in urban environments, after some initial concerns that it would make them overly visible. They also noted students were happy to use iPads in protective waterproof cases in situations where using pen and paper would have been difficult due to e.g. rain.

\section{Distraction}

Could BYOD be a distraction as opposed to supporting learning? Are students distracted by social media or games? One practitioner commented that students were: “Complaining that people using phones for other purposes - difficult to monitor". However, of those who had used BYOD only $4 \%$ of respondents noted it as a concern.

One practitioner in the phone interviews noted: "However, the potential for distraction is greater in the classroom as the students are often passively learning whereas in the field, they are actively learning so more focused on the task at hand." Distraction was also raised as a concern by students when using BYOD in Welsh et al. (2018), however it was seen to be less of a concern in fieldwork than in, for example a lecture setting, as students were actively engaged in activities. Welsh et al. (2018) also noted that poor $3 \mathrm{G}$ and $4 \mathrm{G}$ signals in areas where fieldwork was being done reduces the chance of online distractions. Poor mobile / internet signals were noted as a concern by some practitioners in this study, but in some cases could prove to be beneficial by reducing distractions. 
The benefits of potentially distracting social media apps in fieldwork, for example Facebook and Twitter, were also discussed: "We tend to use a private group on Facebook before going out into the field. On international courses, friendships between students develop between different institutions. Provides them with a longer communication platform. If you lose that then the personal network is lost. Gives longer term connectivity”. Peacock and Bacon (2018) and Welsh et al. (2015) have also highlighted the potential benefits of using Twitter and Facebook in fieldwork to connect students pre, during and post-fieldwork. However, practitioners also need to consider how social media is used for fieldwork. One practitioner who used Facebook in fieldwork noted that students had "Concerns - use of Facebook, would staff see their "personal" activity", potentially leading to an unwillingness to engage.

\section{Removing barriers to BYOD}

Practitioners responding to the survey perceived a lack of support from institutions in implementing BYOD. Practitioners who had used BYOD felt they received little support from their institutions in implementing BYOD. Those who had not used BYOD highlighted the lack of time to set up new exercises, lack of (practitioner) knowledge and difficulty in supporting a range of devices / apps as the main barriers for introducing BYOD. Barriers which institutional and departmental support for BYOD could help to mitigate.

Practitioners who had used BYOD were unsure as to where to get support and information on BYOD and were asked if they received support from organisations external to their institution (e.g. British Ecological Society, Society of Biology and Enhancing Fieldwork Learning). Most felt they had not but, as many respondents commented, were unaware of the support available as they had not specifically sought out support for introducing BYOD. 
Suggestions for support in introducing BYOD included providing information and resources for practitioners, mentoring and person-to-person support (including online support groups and via social media) and sessions at conferences which could provide both information and opportunities to discuss with others who had used BYOD. Time and money were problematic, some practitioners commenting that as the field course they ran was only of short duration they could not justify taking the time to implement BYOD.

Practitioners who had not used BYOD made suggestions as to what could support them in implementing BYOD. This included training courses, financial support and mentors. Practitioners also highlighted the need for resources and information on the apps and resources currently available to support fieldwork and the need for staff to have access to a range of mobile devices so they themselves could learn how to use the technology.

How might BYOD start when practitioners are reluctant due to a lack of time, knowledge or experience? Responses to the survey gave an insight into how BYOD might start in some circumstances. Students initiating BYOD is one example of this. Over half of the practitioners who had not used BYOD indicated that their students had used their own devices, unprompted, in fieldwork. Examples given included taking photos and videos for use in field reports. Perhaps students could initiate BYOD, which practitioners then build on, leading to a more formal use of BYOD in future fieldwork. Another example of indirect introduction of BYOD focuses on the use of various mobile technologies in fieldwork. Mobile technologies of various types are used in variety of fieldwork (for example: Meek et al., 2013; Welsh et al., 2015; Jarvis et al., 2016; Priestnall et al, 2018). 
Of the practitioners who had not used BYOD, just over half had used other mobile / portable technology within fieldwork. This included iPads, GPS and Netbooks / Laptops, apps, e.g. Google earth and Google maps, other standard smartphone and tablet features (such as camera and video recording) laying the groundwork for BYOD to be introduced.

\section{Management of devices}

In the phone interviews those who have used institutional devices identified how challenging it can be managing a university owned set of devices in terms of time and logistics, and welcome the idea that students manage their own. However, both those who have and have not used BYOD identified that managing a range of a devices with different capabilities and operating systems is in itself a challenge and therefore institutional devices with known capabilities may be preferred.

Management of devices in BYOD could include ensuring students have (for example) the appropriate apps on their devices before fieldwork starts, ensuring students have a device on which they can undertake the work and providing technical support and back-ups if required. Again, as with trying to reduce inequality, preparation could be key in these instances.

\section{Changing practice}

Practitioners in both the survey and the phone interviews stated that using BYOD had changed their fieldwork practice. As discussed previously, the SAMR Model offers an opportunity to evaluate the use of technology in teaching and education and track changes in practice through four stages which consider technology use in teaching Substitution; Augmentation; Modification and; Redefinition. The SAMR model was used to explore use and adaptation of course materials and students' reactions to them. 
Thomas and Munge (2017) reflect on the use of the SAMR model in looking at the pedagogical impact of technology use and adoption in fieldwork. They highlight the importance of looking for the unintended consequences of technology adoption and ensuring that the adoption of technology adds to fieldwork teaching and learning

Practitioners taking part in the phone interviews were asked if and how BYOD had changed their practice. Some examples were student-led BYOD, i.e. students using their own device unprompted, and some were using university devices (e.g. iPads) supplied to students in the field. However, all demonstrate either the use or potential use of BYOD. Table 3 lists the changes of practice given in the phone interviews and interpreted in the context of the SAMR model.

Table 3 near here.

Table 3 shows changes in teaching practice resulting from using BYOD (or in a few cases, use of university-owned mobile devices) described by practitioners in the phone interviews. The changes in practice were assigned to one of the four categories of the SAMR model, using the criteria by Puendetura (2009). They show a variety of changes in practice, from students taking photos and videos on their devices and using apps for data collection and species identification, through to redesigning how and what data are collected and how assessment is undertaken. The changes in practice all take advantage of the portable nature of devices in BYOD. None of the changes described fitted into the redefinition aspect of the SAMR model, whereby technology "allows for the creation of new tasks previously inconceivable". Perhaps this highlights how BYOD is emerging as part of teaching in fieldwork and, although changes have been made to 
how students learn and are assessed on fieldwork due to BYOD, there is not yet a shift to an extensive use of BYOD in fieldwork teaching.

Practitioners taking part in the phone interviews gave one of the potential educational benefits of BYOD as new approaches to learning, teaching and assessment in the field. Table 3 brings together some of these new approaches and also highlights small changes to teaching and learning in fieldwork, which those starting out in BYOD could use as an introduction to it.

In the phone interviews practitioners were also asked how they thought BYOD could be used in fieldwork in the future. Two examples focussed on specific aspects of design:

- "Students could design their own fieldwork, their own devices would come into play a lot more as they can see where they can apply them."

- "If you are looking for something specific, might be designing their own app as part of their dissertation if we move away from more traditional dissertations as society demands further skills and interests."

Others considered the potential for BYOD to enable new approaches to learning, and as one practitioner noted in their phone interview;

"If we can facilitate our students rather than instructing our students with the institutional device, if we relinquished some control and embraced BYOD and be willing to live with its limitations and pitfalls maybe that would be a transformative moment."

\section{Conclusions}

The practitioners involved in this study found BYOD beneficial in engaging students in fieldwork and supporting their learning. Student's familiarity with their devices 
enabling them to complete tasks more quickly, engage more with learning and enabling more teaching time in the field was seen as the most beneficial aspect of BYOD by both practitioners who have an have not used BYOD. Students have also identified familiarity with their devices as a benefit of BYOD, supporting learning in the field (Welsh et al., 2018).

Practitioners also highlighted barriers, and potential barriers, to implementing BYOD. Of most concern was the perceived potential for inequality between students (having or not having a device) and inequality between devices (some devices not having the capability for specific tasks). However, when BYOD was used, inequality was not found to be a major issue.

Preparation was thought to reduce the barriers to successful implementation of BYOD, and preparation by both practitioners and students could reduce the potential for inequality (between students and devices), increase time available in the field and reduce technology problems. However, practitioners perceived a lack of support from their own institutions, both for those using and who want to use BYOD, and suggested that resources, information, and mentoring, either in person or online, could support the introduction and use of BYOD.

Using BYOD also lead to changes in teaching and assessment practices and work undertaken by students in the field and post-fieldwork. Support from a high level (for example across departments and institutions) for BYOD could provide an opportunity, not only to support fieldwork, but to engage students through BYOD and encourage them to take their learning beyond formal teaching (Whalley et al., 2020). BYOD has the potential to bring about changes which could enhance fieldwork learning. Encouraging and enabling practitioners to introduce BYOD has the potential to change teaching, learning and assessment processes, supporting student learning. 


\section{Acknowledgements}

We would like to thank all of the practitioners who participated in the surveys and telephone interviews. The 3-year National Teaching Fellowship Project 'Enhancing Fieldwork Learning' was funded the Higher Education Academy.

\section{Disclosure statement}

No potential conflict of interest was reported by the authors.

\section{Funding}

This work was supported by Higher Education Academy.

\section{References}

Afreen, R. (2014). Bring Your Own Device (BYOD) in higher education: Opportunities and challenges. International Journal of Emerging Trends \& Technology in Computer Science, 3(1), 233-236.

Braun, V. \& Clarke, V. (2006) Using thematic analysis in psychology. Qualitative Research in Psychology, 3 (2), 77-101.

Cliffe, A.D. (2017) A review of the benefits and drawbacks to virtual field guides in today's Geoscience higher education environment. International Journal of Educational Technology in Higher Education, 14:28. DOI 10.1186/s41239-0170066-x

Derounian, J.G. (2017) Mobiles in class? Active Learning in Higher Education. DOI: $10.1177 / 1469787417745214$

Fabian, K. \& MacLean, D. (2014) Keep taking the tablets? Assessing the use of tablet devices in learning and teaching activities in the Further Education sector. Research in Learning Technology, 22.

Fletcher, S., France, D., Moore, K. \& Robinson, G. (2007) Practitioner Perspectives on the use of Technology in Fieldwork Teaching. Journal of Geography in Higher Education, 31(2), 319-330.

France, D., Powell, V., Mauchline, A.L., Welsh, K., Park, J. Whalley, W.B. \& Rewhorn, S. (2016): Ability of students to recognize the relationship between 
using mobile apps for learning during fieldwork and the development of graduate attributes. Journal of Geography in Higher Education, 40 (2), 182-192.

France, D. \& Ribchester, C. (2004) Producing websites for assessment: a case study from a level 1 fieldwork module. Journal of Geography in Higher Education, 28(1), 49-62

Fuller, I., Edmondson, S., France, D., Higgitt, D. \& Ratinen, I. (2006) International Perspectives on the Effectiveness of Geography Fieldwork for Learning. Journal of Geography in Higher Education, 30 (1), 89-101, DOI:

$10.1080 / 03098260500499667$

Gardiner, V., \& Unwin, D. J. (1986), Computers and the field class. Journal of Geography in Higher Education, 10(2), 169-179.

Grussendorf, S. (2013) Device ownership, 'BYOD' and social media for learning. Centre for Learning Technology (CLT), The London School of Economics and Political Science, London. Retrieved from http://eprints.1se.ac.uk/id/eprint/51652

Jarvis, C., Tate, N., Dickie, J. \& Brown, G. (2016) Mobile Learning in a Human Geography Field Course. Journal of Geography, 115:2, 61-71. https://doi.org/10.1080/00221341.2015.1026373

Jisc (2016) Supporting an inclusive learner experience in higher education. Retrieved from https://www.jisc.ac.uk/guides/supporting-an-inclusive-learner-experiencein-higher-education

Lumsden, C. (2012) iPads and m-learning at Manchester Medical School. Retrieved from https://community.ja.net/system/files/515/iPads\%20NHSHE2012\%20copy.pdf

Maskall, J., \& Stokes, A. (2009). Designing effective fieldwork for the environmental and natural sciences. York: HEA Subject Centre for Geography, Earth and Environmental Sciences. Retrieved from www. heacademy.ac.uk/resource/designing-effective-fieldwork-environmental-andnatural-sciences

Maw, S.J., Mauchline, A.L. \& Park, J.R. (2011) Biological Fieldwork Provision in Higher Education. Bioscience Education, 17:1, 1-14, DOI: 10.3108/beej.17.1

Meek, S., FitzGerald, E., Priestnall, G. \& Sharples, M. (2013) 'Learning on Field Trips With Mobile Technology. In Kinuthia, W. \& Marshall, S. (eds). On the Move: 
Mobile Learning for Development. Information Age Publishing Inc., Charlotte, NC.

Miller, S. \& Welsh, K. (2017) Bring Your Own Device (BYOD) in Higher Education: Opportunities and Challenges. In René, D., and Aubin, C., (eds.). Mobile Learning: Students' Perspectives, Applications and Challenges. Nova Science Publishers.

Munge, B., Thomas, G. \& Heck, D. (2018) Outdoor Fieldwork in Higher Education: Learning From Multidisciplinary Experience. Journal of Experiential Education, 41(1) 39 -53. DOI: 10.1177/1053825917742165 journals.sagepub.com/home/jee

Newman, J. \& Jones, R. (2008) E-Learning or a-Gimmick? Evaluating the use of rich media in Geography fieldwork. Planet, 20, 47-50.

Nuttall, J., \& Nuttall, L. (2013), Dyslexia and the iPad - Overcoming Dyslexia with Technology. CreateSpace Independent Publishing Platform.

Nykvist, S.S. (2012) The trials and tribulations of a BYOD science classroom. In Yu, Shengquan (Ed.) Proceedings of the 2nd International STEM in Education Conference, Beijing Normal University, Beijing, China, 331-334.

Ofcom (2018) Communications Market Report 2018. Retrieved from https://www.ofcom.org.uk/_data/assets/pdf_file/0022/117256/CMR-2018narrative-report.pdf

Peacock, J. \& Bacon, K.L. (2018) Enhancing student employability through urban ecology fieldwork. Higher Education Pedagogies, DOI: $10.1080 / 23752696.2018 .1462097$

Priestnall, G., FitzGerald, E., Meek, S., Sharples, M. \& Polmear, G. (2019) Augmenting the landscape scene: students as participatory evaluators of mobile geospatial technologies. Journal of Geography in Higher Education, 43:2, 131154.https://doi.org/10.1080/03098265.2019.1599332

Puentedura, R. (2009) Transformation, technology, and education. Retrieved from http://hippasus.com/resources/tte/

Siani, A. (2017) BYOD strategies in higher education: current knowledge, students' perspectives, and challenges. New Directions in the Teaching of Physical Sciences, 12 (1). Retrieved from https://www108.lamp.le.ac.uk/ojs1/index.php/newdirections/article/view/824/2261 
Stagg, B.C. \& Donkin, M.E. (2017) Apps for angiosperms: the usability of mobile computers and printed field guides for UK wild flower and winter tree identification. Journal of Biological Education, 51(2), 123-135.

Thomas, G.J. \& Munge, B. (2017) Innovative outdoor fieldwork pedagogies in the higher education sector: Optimising the use of technology. Journal of Outdoor and Environmental Education, 20(1), 7-13.

Thomas, R.L. \& Fellowes, M.D.E. (2017) Effectiveness of mobile apps in teaching field-based identification skills. Journal of Biological Education, 51(2), 136143.

Welsh, K.E., Mauchline, A.L., Park, J.R., Whalley, W.B. \& France, D. (2013) Enhancing fieldwork learning with technology: practitioner's perspectives. Journal of Geography in Higher Education, 37(3), 399-415.

Welsh, K.E., Mauchline, A.L., Powell, V., France, D., Park, J.R. \& Whalley, W.B. (2015) Student perceptions of iPads as mobile learning devices for fieldwork. Journal of Geography in Higher Education, 39(3), 450-469.

Welsh, K.E., Mauchline, A.L., France, D., Powell, V., Whalley, W.B. \& Park, J. (2018): Would Bring Your Own Device (BYOD) be welcomed by undergraduate students to support their learning during fieldwork? Journal of Geography in Higher Education, 42(3), 356-371.

Whalley, W. B., France, D., Park, J. R., Mauchline, A., Powell, V., \& Welsh, K. E. (2014). iPad use in Fieldwork: Formal and informal use to enhance pedagogic practice in a Bring Your Own Technology World. Proceedings of the 1st international conference on the use of iPads in higher education, March 2014, Paphos, Cyprus. Retrieved from http://ipadsinhe.org/ihe-2014-paphos

Whalley, W.B., Mauchline, A.L., France, D., Park, J. and Welsh, K. (2018) The iPad six years on: Progress and Problems for Enhancing Mobile Learning with Special Reference to Fieldwork Education. In: Crompton, H. \& Traxler, J. (Eds) Mobile Learning in Higher Education: Challenges in context, (pp. 8-18), Routledge. Whalley, B., France, D., Park, J., Mauchline, A., \& Welsh, K. (2020). Developing Active Personal Learning Environments on Smart Mobile Devices. In: Arai, K., Bhatia, R. \& Kapoor, S. (Eds.), Proceedings of the Future Technologies Conference (FTC) 2019 (Vol. 2, pp. 871-889). Cham, Switzerland: Springer Nature. 
Wishart, J. (2011) Handheld mobile devices in initial teacher training. In: Traxler, J. and Wishart, J. (Eds), Making mobile learning work: case studies of practice Subject Centre for Education, ESCalate. Retrieved from https://researchinformation.bristol.ac.uk/files/13087700/Making Mobile Learning Work.pdf Woodcock, B., Middleton, A., \& Nortcliffe, A. (2012). Considering the Smartphone learner: An investigation into student interest in the use of personal technology to enhance their learning. Student Engagement and Experience Journal, 1(1), 115.

Table 1: Perceived benefits of using BYOD from the survey.

Table2: Challenges and barriers to using BYOD from the survey.

Table 3. Changes in teaching practice as a result of BYOD or device use in the field discussed in the phone interviews interpreted in the context of the SAMR model.

Figure 1: Word cloud of responses, from all phone interview respondents, to "Do you believe there are any educational benefits of using BYOD for student learning in fieldwork education? Please elaborate." Larger words indicate more frequent responses. 